\title{
O conhecimento tradicional sobre plantas melitófilas em comunidades rurais do município de Sigefredo Pacheco, Piauí
}

\section{The traditional knowledge about melitophile plants in rural communities in the city of Sigefredo Pacheco, Piauí}

\author{
Ederson de Sousa Martins ${ }^{1}$, Patrícia Pereira de Oliveira ${ }^{2}$, Leide Dayane Viana da Silva ${ }^{3}$, José Rodrigues de Almeida Neto $^{4}$
}

Resumo: O conhecimento sobre plantas com potencial melitófilo a cada dia ganha espaço nas pesquisas, assim é em comunidades rurais que estas informações são coletadas. Desta forma a Etnobotânica, que estuda a relação de grupos humanos e as plantas se torna fundamental, pois, levanta-se informações sobre as espécies visitadas por abelhas como também os apicultores e meliponicultores, auxiliando na proteção do meio ambiente, em especial a espécies de árvores nativas e diferentes grupos de abelhas. Objetivou-se realizar um levantamento etnobotânico em relação ao conhecimento dos moradores de duas comunidades rurais do município de Sigrefredo Pacheco, Estado do Piauí, sobre plantas melitófilas. O estudo foi realizado através de entrevistas em todas as residências (41) das duas comunidades, totalizando 69 entrevistados. Foram 31 espécies de plantas citadas, tendo destaque a família Leguminosae. As espécies mais citadas foram: Croton blanchetianus Baill. (25) e Hyptis suaveolens (L.) Poit. (25), sendo as espécies nativas mais bem representadas (77,4\%). Observou-se que a parcela jovem foi a que teve menor participação e em relação ao gênero, percebeu-se que os homens apresentaram maior número de citação de plantas que as mulheres. Conclui-se que o conhecimento sobre plantas melitófilas é presente entre os moradores das comunidades, que os mesmos conhecem práticas favoráveis à conservação da flora melitófila, porém, estas não se encontram difundidas na comunidade. Faz-se necessário conhecer cada vez mais o conhecimento sobre flora apícola de comunidades rurais, a fim de resgatar e valorizar esse saber, bem como medidas conservacionistas locais.

Palavras-chave: Etnobotânica; Apicultura; Conservação; Flora apícola.

\begin{abstract}
The knowledge about plants with melitophile potential is highlighted in the research field, this way; these pieces of information are collected in the rural areas. Thus, ethnobotany, which studies the relation between human groups and plants, is fundamental, because it brings information about the species visited by bees as well as beekeepers and meliponiculturers, helping with environmental protection, especially native tree species and different bee groups. The objective of this study was to conduct an ethnobotanical survey about the knowledge the residents of two rural communities in the city of Sigrefredo Pacheco, state of Piauí, about melitophile plants. The study was conducted through interviews in every house (41) of the two communities, totalizing 69 interviewees. 31 species were cited, and the family Leguminosae was highlighted.the most cited species were: Croton blanchetianus Baill. (25) and Hyptis suaveolens (L.) Poit. (25), in which the native species stood out $(77,4 \%)$. It is possible to observe that the younger portion had the smaller participation and about gender, it is noticeable that men presented a major number of citation addressing plants than women. The study concludes that the knowledge of melitophile plants is present among the residents of the communities, that they know the profitable practices to the conservation of the melitophile flora, though; they are not overspread in the community. It is necessary to know more and more the knowledge about apicultural flora in rural communities, in order to rescue and value this knowledge, as well as local conservation measures.
\end{abstract}

Key word: Ethnobotany; Beekeeping; Conservation; Flora apiculture.

\footnotetext{
*Autor para correspondência

Recebido para publicação em 22/08/2016; aprovado em 11/06/2017

${ }^{1}$ Graduado em Licenciatura Plena em Ciências Biológicas, Especialista em Gestão Ambiental pelo Instituto Superior de Educação São Judas Tadeu, TeresinaPI; (86) 98865-8101, edersonbio@ hotmail.com

${ }^{2}$ Graduada em Licenciatura Plena em Ciências Biológicas, Universidade Estadual do Piauí, patriciapereira26@outlook.com

${ }^{3}$ Graduada em Licenciatura Plena em Ciências Biológicas, Universidade Estadual do Piauí, dayannebella13@gmail.com

${ }^{4}$ Mestre em Desenvolvimento e Meio Ambiente pela Universidade Federal do Piauí, Professor da Faculdade de Tecnologia de Teresina-Faculdade CET, almeidanetobio@hotmail.com
} 


\section{INTRODUÇÃO}

No Brasil, a maior parte do conhecimento em relação à utilidade de plantas nativas se refere à Floresta Amazônica, pela sua grande importância para o cenário mundial (NEGRELLE; FORNAZZARI, 2007). Porém, a cada dia novas pesquisas vêm sendo desenvolvidas em todo o País, especialmente na região Nordeste e em áreas de cerrado e caatinga, devido a crescente utilização, e necessidade, dos recursos naturais pelo homem.

A Etnobotânica é vista como uma ciência que estuda e procura captar as diferentes dimensões da relação de grupos humanos com as plantas (VIU et al., 2010). No caso do Brasil, e de outros países em desenvolvimento, a construção e a transformação da Etnobotânica ocorre em um cenário de diversidade cultural e biológica, o que torna os recursos um patrimônio de imenso valor, incluindo plantas de interesse e potencial de mercado que podem ser prováveis fontes de renda com sustentabilidade ambiental (OLIVEIRA et al., 2009).

As comunidades rurais são vistas como espaços para o estudo da Etnobotânica, pois como ambientes culturalmente tradicionais, são nesses espaços que se encontra um grande conhecimento dos ciclos biológicos e do uso de recursos naturais renováveis que são transmitidos de geração para geração, vistos como instrumento de sobrevivência e conservação da diversidade biológica (COSTA, 2013). Assim, é através dos estudos etnobotânicos que se tem conhecimento das práticas realizadas pelos moradores direcionados às plantas, na qual boa parte delas tendem a preservar a natureza, uma vez que os praticantes já têm incorporado em sua vivência a importância da mesma para a sua permanência naquele local.

Todo o conhecimento passado de geração após geração se encontra intimamente enraizado na história local de uma comunidade, e as comunidades tradicionais, notadamente rurais, são as que melhor detêm este saber. As comunidades consideradas tradicionais são chamadas assim por possuir alguns fatores importantes como, uma autoidentificação própria, atividade econômica, vínculos históricos e a ocupação de um determinado território para a sua reprodução cultural, são estas características específicas, que as tornam um grupo tradicional (GIRALDE; HANAZAKI, 2010).

A relação entre abelhas e planta é mercada pela necessidade que o inseto possui em visitá-la com a finalidade de desfrutar dos seus produtos ofertados, pois, as abelhas necessitam e são dependentes das flores, uma vez que, é através destas que obtém pólen, néctar, óleos, fragrâncias e outros recursos utilizados tanto pelos adultos quanto para suas larvas. E é com base nestas observações que se faz necessário conservar a vegetação local, pois os recursos florais são obtidos por uma variedade de grupos que forrageiam em horários diferentes, podendo concentrar-se em certas espécies de plantas (SANTOS et al., 2006).

As plantas melíferas, melitófílas ou flora apícola são aquelas que fornecem produtos para as abelhas (TORQUATO, 2006; VIDAL et al., 2008; PEREIRA JÚNIOR et al., 2012). Deste modo, observa-se que o levantamento das espécies vegetais é de extrema importância, sejam elas de interesse econômico ou de uso tradicional, uma vez que as mesmas podem auxiliar nos estudos de manejo integrado e também orientar a exploração racional dos recursos naturais disponíveis (SYLVESTRE; ROSA, 2002). Segundo Mendonça et al., (2008), a diversidade da flora brasileira, associada à extensão territorial e a variabilidade climática, faz com que o Brasil passe a ter um grande potencial apícola, fazendo com que os apicultores colham mel durante todo o ano.

O conhecimento acerca das plantas melitófilas em comunidades tradicionais se faz necessário, tornando-se subsídio para a prática no que diz respeito a conservação do meio ambiente, tanto de espécies vegetais como de toda uma cadeia ecológica. Para Silva et al., (2014), as abelhas coletam basicamente néctar e pólen das flores, com isso, estas dependem da disponibilidade da florada local, sendo assim, é indispensável o conhecimento em relação aos recursos florais existentes em uma localidade.

Para Vidal et al., (2008), a flora do Brasil é muito rica e diversificada, mas o seu conhecimento, especificamente, quanto à flora apícola nordestina, necessita ser mais investigada, tendo em vista que essa região é reconhecida como uma das áreas de maior potencial para a apicultura no País. Demartelaere et al., (2010), descreve que o registro da flora apícola deverá ser de caráter regional, pois as espécies consideradas excelentes produtoras de néctar em uma região podem não ser em outra. Na concepção de Salis et al., (2015), para o desenvolvimento da apicultura e da meliponicultura em uma certa região, se faz necessário conhecer a flora melífera e os recursos florais disponíveis, pois esses variam em função do bioma e das estações do ano.

Diversos trabalhos etnobotânicos em comunidades tradicionais foram realizados no estado do Piauí, mas, com a finalidade de descrever plantas com potencial melitófilo, destacam-se os trabalhos de: Costa (2005); Chaves et al., (2006a); Torquato (2006); Costa e Castro (2007); Sousa (2007); Soares (2007).

Para a investigação sobre a flora melitófila, pode-se empregar diversas técnicas, uma destas consiste em observação direta da planta visitada pelas abelhas nativas ou africanizadas (MORETI et al., 2006; PINHEIRO et al., 2008; VIEIRA et al., 2008), ou pela observação indireta por meio da análise do pólen apícola (MENDONÇA et al., 2008) e dos grãos de pólen presentes no mel (MENDONÇA et al., 2008; SODRÉ et al., 2008; BENDINI; SOUZA, 2008) ou na própolis (SANTOS et al., 2003). Contudo, o homem também detém conhecimento sobre as espécies botânicas visitadas pelas abelhas, pois o mesmo, com a observação direta consegui identificar em seu meio, as preferências das abelhas em visitas florais.

Objetivou-se realizar um levantamento etnobotânico em relação ao conhecimento dos moradores de duas comunidades rurais, no interior do nordeste do Brasil, a respeito de plantas melitófilas, especificando as variedades de plantas melíferas que são conhecidas pela população local; verificando se existe plantio para o fim melífero e investigando a existência de práticas conservacionistas em relação a tais plantas.

\section{MATERIAL E MÉTODOS}

O presente estudo foi desenvolvido em duas comunidades rurais, Olho d'água da Fazenda e Poço do Jatobá, pertencentes ao município de Sigefredo Pacheco,

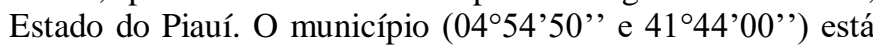
a uma distância de $160 \mathrm{~km}$ da capital Teresina, com uma área 
de $966,989 \mathrm{~km}^{2}$ e uma população de 9,619 habitantes, e com uma estimativa de 9,854 hab para 2015, corresponde a uma densidade demográfica de 9,95 habitante $/ \mathrm{km}^{2}$, onde 6,443 pessoas residem na zona rural e 3, 176 residem na zona urbana. (IBGE, 2010).

O município tem como limite ao norte as cidades de Jatobá do Piauí, Mílton Brandão, Juazeiro do Piauí, ao sul o Novo Santo Antônio, ao leste as cidades de Castelo do Piauí e ao oeste os municípios de Campo Maior e Jatobá do Piauí. A região pertence ao bioma Caatinga; com transições típicas do complexo vegetacional de Campo Maior, apresentando vegetação do tipo parque e campo cerrado. Quanto a sua caracterização morfoclimáticas, o município possui um clima Tropical alternadamente úmido e seco, com duração do período seco de seis meses, com temperaturas médias entre $26^{\circ} \mathrm{C}$ a $35^{\circ} \mathrm{C}$, seu solo é do tipo latossolo vermelho-amarelo podzólico associados a areias quartzosas e solos indiscriminados tropicais (IBGE, 2010; CEPRO, 2013).

Em relação as comunidades, em Olho d'agua da Fazenda, suas residências se encontram bem próximas umas das outras, com construções de adube em maioria, possuindo água encanada e fossa séptica, os moradores são habituados a queimar seu lixo nos quintais. Uma boa parte dos moradores possui ajuda do governo, como o acesso aos programas sociais. Na comunidade Poço do Jatobá, as mesmas condições sociais e econômicas são verificadas, porém com as residências mais afastadas umas das outras, chegando em alguns casos, a distância de um quilometro entre um e outra. Em ambas as comunidades, os seus moradores praticavam a apicultura ou a meliponicultura, porém, atualmente não se pratica tal atividade.

Para a definição do universo amostral de entrevistados nas comunidades, optou-se seguir a metodologia sugerida por Begossi et al., (2004), que orienta para estudos etnobiológicos em comunidades onde o número de famílias é até 50, proceder entrevistas em todas as famílias. Portanto, todas as casas das comunidades Poço do Jatobá (23) e Olho D’água da Fazenda (18) foram visitadas, fazendo assim um censo de residência local.

Com relação às entrevistas as mesmas se deram com aplicação de um formulário semiestruturado abordando três módulos, adaptado de Silva (2010): 1- dados socioeconômicos, 2- dados etnobotânicos e 3- dados sobre percepção sobre meio ambiente.

Como critério de inclusão dos entrevistados nas residências visitadas, entrevistou-se apenas os moradores maiores de idade que se disponibilizassem a dar entrevistas, e para isso, foi adotado as faixas etárias definidas pelo IBGE (2010) para as faixas etárias: jovens (18 a 24 anos); adultos (25 a 59 anos) e os idosos (a partir de 60 anos).

No momento das citações de plantas melitófilas, utilizou-se, em alguns casos, a técnica de turnê-guiada (BERNARD, 1988). Essa técnica foi aplicada nos quintais e matas próximas as residências, para a coleta do material, obedecendo as regras de coleta para plantas e herborização (MORI et al., 1989). Ainda, como instrumento de auxilio se utilizou de registros fotográficos. Para a identificação botânica se utilizou de análises morfológicas, consultas literárias e comparações com materiais incorporados ao acervo do Herbário Graziela Barroso (TEPB), da
Universidade Federal do Piauí (UFPI), onde o material desta pesquisa se encontra devidamente incorporado.

O processo de tabulação e análise de dados foi feita através de programa Microsoft Excel. A nomenclatura apresentada segue à proposta do sistema de classificação de Cronquist (1981), com exceção para a família Leguminosa e, que obedeceu às normatizações do sistema de Judd et al., (1999). As grafias e nomes dos autores das espécies foram corrigidas utilizando-se o sítio do MOBOT (2016) como consulta, e a origem e distribuição das espécies foi verificada através do sítio da FLORA DO BRASIL (2016).

\section{RESULTADOS E DISCUSSÃO}

Com relação as espécies de plantas melitófilas, foram levantadas 31 espécies, distribuídas em 17 famílias botânicas (Tabela 01). Deste modo, observa-se um número de citação menor em comparações com outros trabalhos semelhantes, como o de Santos et al., (2006), que observou em seu trabalho 51 espécies vegetais, pertencentes a 25 famílias botânicas visitadas por abelhas Apis mellifera L. 1758; Viana et al., (2006), destacou 97 espécies vegetais; Rodarte et al., (2008) identificou 42 espécies, distribuídas em 24 famílias botânicas e Silva (2010), encontrou na categoria melitófila um total de 45 espécies em 24 famílias botânicas.

Para o levantamento florístico e estudos botânicos realizados no Estado do Piauí sobre a flora melífera, tem-se registro para Costa (2005) na qual obteve 173 espécies melífera, Chaves et al., (2006b) na qual coletaram 29 espécies distribuídas em 15 famílias, Torquato (2006) identificou 93 espécies, distribuídas 34 famílias, Sousa (2007), listou 35 espécies vegetais, em 19 famílias e Soares (2007), identificou 40 espécies associadas a abelhas.

Dentre as espécies listadas, as mais citadas pelos moradores foram: Croton blanchetianus Baill. (marmeleiro) (25) e Hyptis suaveolens (L.) Poit. (bamburral) (25) e as menos citadas, ou seja, com apenas (1) uma citação foram: Helianthus annuus L. (girassol); Aspidosperma pyrifolium Mart. (pereira); Cenostigma macrophyllum Tul. (caneleiro); Amburana cearensis (Allemão) A.C.Sm. (imburana); Psidium guajava L. (goiaba); Eragrostis pilosa (L.) P. Beauv.(capim); Curatella americana L. (sambaiba); Parkia platycephala Benth. (faveira); Scoparia dulcis L. (vassourinha); Machaerium acutifolium Vogel (jacarandá); Curcubita pepo L. (abóbora), Malpighia glabra L. (acerola) e Terminalia fagifolia Mart. (chapada).

Com relação à riqueza de espécies melitófilas apontadas pelos moradores das duas comunidades, pode-se discutir a partir da distribuição das duas formações vegetais encontradas para o Estado. O Cerrado, ocorrendo na região sudoeste e parte do extremo sul, ampliando-se nas regiões centro-leste e norte e a Caatinga, que incluem as espécies arbórea, arbustiva/arbórea ou arbustiva; com densidades variáveis ocorre na faixa leste, no centro norte e no sudeste do Estado (ALEIXO et al., 2014). Para Lucena et al. (2011), o cenário da caatinga, consiste em um local ideal para estudos etnobotânicos, uma vez que compreende uma fascinante diversidade biológica e cultural. 
Tabela 1. Espécies botânicas visitadas por abelhas. Nome vernácula (nv); Hábito (hab): erv = erva; arb = arbusto; sub = subarbusto; arv = árvore; lia= liana; Status $(S t)$ : e = exótica; $\mathrm{n}=$ nativa; Frequência relativa das citações $(\mathrm{FRC})$; TEPB: número de registro (Herbário Graziela Barroso/UFPI); il. = identificada no local.

\begin{tabular}{|c|c|c|c|c|c|}
\hline $\begin{array}{l}\text { Família } \\
\text { Espécie/autor }\end{array}$ & TEPB & NV & $\mathrm{Hab}$ & FRC & $\mathrm{St}$ \\
\hline \multicolumn{6}{|l|}{ Anacardiaceae } \\
\hline Anacardium occidentale L. & 30.958 & caju & $\operatorname{arv}$ & $6,6 \%$ & $\mathrm{n}$ \\
\hline Mangifera indica $\mathrm{L}$. & 31.067 & manga & $\operatorname{arv}$ & $2,0 \%$ & $\mathrm{e}$ \\
\hline Myracrodruon urundeuva M.Allemão & 31.068 & aroeira & $\operatorname{arv}$ & $4,6 \%$ & $\mathrm{n}$ \\
\hline Spondias tuberosa Arr. Cam. & 31.105 & umbu & $\operatorname{arv}$ & $1,0 \%$ & $\mathrm{n}$ \\
\hline Mimosa caesalpiniifolia Benth. & 31.069 & sabiá & $\operatorname{arv}$ & $6,6 \%$ & $\mathrm{n}$ \\
\hline Piptadenia moniliformis Benth. & 31.106 & cantanduva & $\operatorname{arv}$ & $2,0 \%$ & $\mathrm{n}$ \\
\hline \multicolumn{6}{|l|}{ Apocynaceae } \\
\hline Aspidosperma pyrifolium Mart. & 31.103 & pereira & $\operatorname{arv}$ & $0,5 \%$ & $\mathrm{n}$ \\
\hline \multicolumn{6}{|l|}{ Asteraceae } \\
\hline Helianthus annuus L. & il. & girassol & erv & $0,5 \%$ & $\mathrm{e}$ \\
\hline \multicolumn{6}{|l|}{ Bignoniaceae } \\
\hline Handroanthus impetiginosus (Mart. ex DC.) Mattos & 30.956 & ypê-roxo & $\operatorname{arv}$ & $8,2 \%$ & $\mathrm{n}$ \\
\hline \multicolumn{6}{|l|}{ Combretaceae } \\
\hline Combretum leprosum Mart. & 31.095 & mufumbo & arb & $4,6 \%$ & $\mathrm{n}$ \\
\hline Terminalia fagifolia Mart. & 31.096 & chapada & $\operatorname{arv}$ & $0,5 \%$ & $\mathrm{n}$ \\
\hline \multicolumn{6}{|l|}{ Convolvulaceae } \\
\hline \multicolumn{6}{|l|}{ Cucurbitaceae } \\
\hline Curcubita pepo L. & 31.093 & abóbora & lia & $0,5 \%$ & $\mathrm{e}$ \\
\hline \multicolumn{5}{|l|}{ Dilleniaceae } & $\mathrm{n}$ \\
\hline \multicolumn{6}{|l|}{ Euphorbiaceae } \\
\hline Croton blanchetianus Baill. & 30.963 & marmeleiro & $\operatorname{arv}$ & $12,8 \%$ & $\mathrm{n}$ \\
\hline Croton campestres A.St.-Hil. & 31.091 & velame & sub & $0,5 \%$ & $\mathrm{n}$ \\
\hline \multicolumn{6}{|l|}{ Lamiaceae } \\
\hline Hyptis suaveolens (L.) Poit. & 30,961 & bamburral & erv & $12,8 \%$ & $\mathrm{n}$ \\
\hline \multicolumn{6}{|l|}{ Leguminosae-Caesalpinioideae } \\
\hline Bauhinia ungulata $\mathrm{L}$. & 30.959 & mororó & arb & $8,2 \%$ & $\mathrm{n}$ \\
\hline Cenostigma macrophyllum Tul. & 31.100 & caneleiro & arb & $0,5 \%$ & $\mathrm{n}$ \\
\hline Libidibia ferrea (Mart. ex Tul.) L.P.Queiroz & 31.084 & jucá & $\operatorname{arv}$ & $1,0 \%$ & $\mathrm{n}$ \\
\hline \multicolumn{6}{|l|}{ Leguminosae/Minosoideae } \\
\hline \multicolumn{6}{|l|}{ Leguminosae/Papilionoideae } \\
\hline Amburana cearensis (Allemão) A.C.Sm. & 30.960 & imburana & $\operatorname{arv}$ & $0,5 \%$ & $\mathrm{n}$ \\
\hline Vatairea macrocarpa Ducke & 30.957 & amargoso & $\operatorname{arv}$ & $1,0 \%$ & $\mathrm{n}$ \\
\hline Machaerium acutifolium Vogel & il. & jacarandá & $\operatorname{arv}$ & $0,5 \%$ & $\mathrm{n}$ \\
\hline \multicolumn{6}{|l|}{ Malpighiaceae } \\
\hline Malpighia glabra L. & 31.080 & acerola & arb & $0,5 \%$ & $\mathrm{e}$ \\
\hline \multicolumn{6}{|l|}{ Myrtaceae } \\
\hline Psidium guajava $\mathrm{L}$. & 31.077 & Goiaba & $\operatorname{arv}$ & $0,5 \%$ & $\mathrm{n}$ \\
\hline \multicolumn{6}{|l|}{ Passifloraceae } \\
\hline Passiflora edulis Sims. & 31.072 & maracujá & lia & $1,5 \%$ & $\mathrm{n}$ \\
\hline \multicolumn{6}{|l|}{ Poaceae } \\
\hline Eragrostis pilosa (L.) P. Beauv. & 31.071 & Capim & erv & $0,5 \%$ & $\mathrm{n}$ \\
\hline \multicolumn{6}{|l|}{ Rosaceae } \\
\hline Licania rigida Benth & 31.104 & Oiticica & $\operatorname{arv}$ & $8,7 \%$ & $\mathrm{n}$ \\
\hline \multicolumn{6}{|l|}{ Rutaceae } \\
\hline Citrus aurantium L. & 31.073 & laranja & $\operatorname{arv}$ & $1,0 \%$ & $\mathrm{e}$ \\
\hline Citrus limonum Risso & 31.074 & limão & arb & $1,0 \%$ & $\mathrm{e}$ \\
\hline
\end{tabular}


No presente estudo, a família que teve maior representatividade foi Leguminosae (7), Anacardiaceae com (6) seis espécies, seguida por Combretaceae, Euphorbiaceae e Rutaceae com (2) duas citações para cada família. Dentre as duas famílias mais bem representadas neste estudo, a Leguminosae merece destaque, pois foi a mais citada como plantas melitófilas nos trabalhos de Santos et al., (2006), Chaves et al., (2006b), Torquato (2006), Sousa (2007) e Silva (2010), mostrando assim, a importância exercida pela família para as abelhas. Segundo Sampaio (1995), a vegetação da caatinga ainda é um pouco desconhecida, sendo Leguminosae e Eufhorbiaceae as famílias que figuram com maior número de espécie nesse bioma. Com relação a família Leguminosae, esta consiste em uma das mais representativas da Caatinga, sendo constituída por 293 espécies que estão distribuídas entre suas três subfamílias, Faboideae, Caesalpinioideae e Mimosoideae (GIULIETTI et al., 2004).

As espécies nativas foram as mais bem representadas com 77,4\% das espécies citadas e 22,6\% exóticas, ou seja, os moradores perceberam que as abelhas possuem uma melhor preferência por árvores nativas sendo estas mais visitadas. $\mathrm{O}$ status é visto como umas das características que tem influência sobre a produção na apicultura e na meliponicultura, segundo Monte et al., (2013). Atualmente o Estado do Piauí tem seu mel como um importante produto na pauta de exportação, para Moura (2006), isso se deve a existência de floradas nativas, que são ricas em plantas melíferas, e pela ausência de contaminantes químicos o que favorece a produção de um mel de excelente qualidade. De acordo com Pereira Júnior et al., (2012), os atuais meliponíneos, o grupo de abelha que compõem a meliponicultura, dependem ainda mais das características climáticas e florísticas de suas respectivas regiões de origem, mostrando assim, a importância das espécies nativas para os grupos destas abelhas. Trovão et al., (2009), descrevem que ao analisar a florística observaram que a maioria das espécies visitadas pelas abelhas são nativas da Caatinga. Sendo assim, o conhecimento se faz necessário para a preservação e a multiplicação destas plantas melíferas (SODRÉ et al., 2008). Conhecer detalhadamente a floração das plantas nativas auxilia grandemente na determinação das espécies vegetais que contribuem para formação do mel produzido em uma determinada região (BENEVIDES; CARVALHO, 2009).

Ao comparar a média de citação entre os gêneros, verificou-se que, a média para os homens foi de 4,38 e para as mulheres 4,25. Dentre as 31 espécies de plantas melitófilas citadas, os moradores da comunidade Olho d'agua da Fazenda mencionaram 18 espécies, que são visitadas por abelhas e no Poço do Jatobá o número de citações foi de 26 espécies. Também pôde-se observar que 13 destas espécies foram citadas apenas na comunidade Poço do Jatobá e cinco delas foram citadas apenas para a comunidade Olho d'agua da Fazenda. Nas duas comunidades estudadas, observou-se que o conhecimento sobre a flora melitófila se encontra bem acentuado entre os moradores, entendendo assim, que os estudos que procuram enfocar as etnociências, especialmente o conhecimento popular sobre a flora, como a etnobotânica, são fundamentais para estes locais, pois a mesma busca entender o mundo como é percebido, conhecido e significado por diversas culturas humanas (BEGOSSI, 1993; TORRES et al., 2009). Com essa mesma perspectiva, Albuquerque e Andrade (2002) entendem que a variedade de plantas, o uso, a cultura tradicional, assim como os elementos a elas associados merecem ser pesquisados, protegidos e valorizados para que se possa implicar em manejos ambientais que sejam capazes de garantir a total sustentabilidade e a conservação da cobertura vegetal e melhorar a qualidade de vida do homem nas áreas onde habitam.

Observa-se que a parcela jovem foi a que teve menor participação, tanto no que se refere à quantidade de entrevistados, pois foi a menor entre os três grupos (jovens, adultos e idosos), como em relação ao número de plantas citadas, o que lhes confere uma média de 1,5 de citação, e a adulta foi a que teve maior média sendo representada por 3,23 (Figura 1). Assim, verifica-se que os jovens tiveram a menor participação no que se refere a citações de plantas melitófilas. Vieira (2008), cita que se faz necessário estimular os jovens, pois são os futuros detentores dos conhecimentos locais, preservando assim as tradições da região. A riqueza de conhecimento acerca da flora melitófila, é de extrema importância, principalmente em regiões cuja biodiversidade vegetal é grande e que já se percebe a perda do conhecimento por parte da geração mais jovens, sendo assim, a mesma merece destaque em estudos etnobotânicos. Gandolfo e Hanazaki (2011), também entendem que a Etnobotânica contribui no resgate do conhecimento tradicional em locais com dinâmica ambiental e social, com o intuito de evitar a perda dos saberes tradicionais em um cenário de mudanças socioeconômicas.

Figura 1. Média de citação de espécies melitófila por faixa etária entre moradores de comunidades rurais do município de Sigefredo Pacheco, Estado do Piauí.

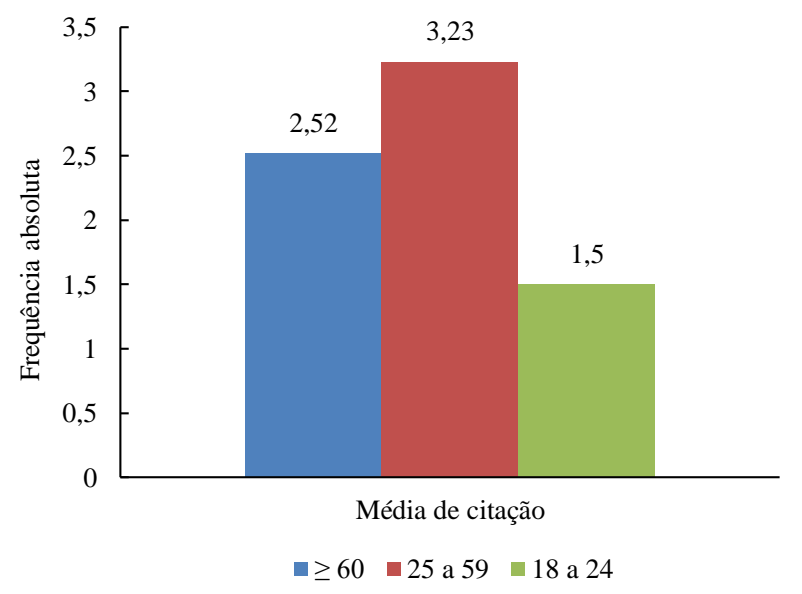

Ao analisar as citações de plantas em relação ao gênero, percebe-se que os homens apresentaram maior número de citação de plantas que as mulheres. Segundo Silva et al., (2015), de modo geral, as mulheres dominam o conhecimento das plantas que crescem perto das residências, já os homens possuem o conhecimento mais sobre plantas que crescem sobre os campos, porém, esta especialidade não é rígida, algumas mulheres conhecem os recursos que o campo oferece, tanto quanto, seus maridos, assim, tanto as mulheres como homens, tradicionalmente, têm funções distintas, e cada um dos sexos se move através estes espaços de maneira diferentes.

Observou-se que a maior ocorrência das citações de plantas como P. guajava (goiaba), Anacardium occidentale L. (caju), Mangifera indica L. (manga), Citrus aurantium L. 
(laranja), Passiflora edulis Sims. (maracujá), Citrus limonum Risso (limão), Spondias tuberosa Arr. Cam. (umbu), Curcubita pepo L. (abóbora) e M. glabra (acerola) como potenciais plantas melitófilas, foram descritas por mulheres, uma vez que todas estas se encontraram nos quintais das residências, o que confirma terem conhecimento referente as plantas que cercam a residência e que situam em seus quintais. Albuquerque et al., (2008) ressalta que essa diferença em relação ao uso e o conhecimento tradicional de plantas é esperado entre grupos de homens e mulheres em determinada região. Camou-Guerreiro et al., (2008) afirmam que as preferências de plantas uteis podem ser distintas entre o gênero. E, corroborando essa ideia, Ayantunde et al., (2008), dizem que essas diferenças no conhecimento local em relação ao sexo podem se assentar pelas diferenças estruturais política e econômica, como o trabalho diferenciado entre homens e mulheres.

O homem necessita do meio para a sua sobrevivência, dele, retira os recursos naturais que lhes servirá para realizar diversas atividades, e lhes propicia condições o suficiente para a sua permanência no local onde vive, assim a sociedade tende a acumular informações sobre o ambiente que a cerca, o que lhes possibilita interagir com ele para prover suas necessidades de sobrevivência (SILVA et al., 2015). Com o acúmulo de informações, e com a utilização do meio para suprir suas necessidades em diferentes aspectos, as atividades deverão vir com um pensamento conservacionista, ou seja, usar de uma forma que possa retirar os recursos no qual necessitam, sem prejudica-lo, praticando assim, o manejo sustentável.

Nas áreas rurais, a interação do homem com a natureza se encontra bem entrelaçada, pois a sobrevivência do homem no campo muitas vezes depende dos seus recursos. Com relação aos recursos naturais, estas comunidades possuem formas peculiares de manejo, que muitas vezes não visam de uma forma direta o lucro, mas sim a reprodução cultural e social, além da forma de ver o mundo natural, que é marcada pela ideia de associação com a natureza e a sua dependência de seus ciclos (GRZEBIELUKA, 2012).

De acordo com os resultados das entrevistas sobre a importância de se conservar a flora melitófila, pode-se observar um alto percentual em relação ao pensamento conservacionista, pois $84 \%$ (58), afirmaram que acham importante conservar as espécies melitófilas (Figura 2). Percebe-se que o mencionado vai de encontro com a vida dos entrevistados, uma vez que são agricultores, e já conhecem as práticas necessárias para garantir o seu sustento, sem que ocorra grandes prejuízos a natureza. Vieira (2008) afirma que há uma grande necessidade de estudos que tenham por objetivo resgatar o saber acumulado por comunidades tradicionais, pois esse conhecimento, muitas vezes herdado dos mais velhos, poderá levá-los a um uso sustentável do meio.

Segundo as informações obtidas durante as entrevistas, algumas informações foram vistas como importantes para os dados acima citados, algumas das citações de fala dos entrevistados foram:
Quadro 1. Relato sobre a Importância da conservação das espécies vegetais melitófilas pelos moradores de comunidades rurais do município de Sigefredo Pacheco, Estado do Piauí.

"Pra mim, é importante conservar as árvores que estas abelhas visitam, pois muitas delas são frutíferas e que também nos fornece frutos para a nossa alimentação" (Entrevistado 45).

"As abelhas e as árvores dependem uma da outra, pois se uma determinada árvore se deixar de existir naquele local, as abelhas também sumiram, deixando assim de existir naquela região, neste caso, é importante não realizar o desmatamento, pois isso, colabora para a diminuição de muitas espécies de árvores que as abelhas visitam para poder produzir seu mel" (Entrevistado 28).

Figura 2. Importância da conservação das espécies vegetais melitófilas pelos moradores de comunidades rurais do município de Sigefredo Pacheco, Estado do Piauí.

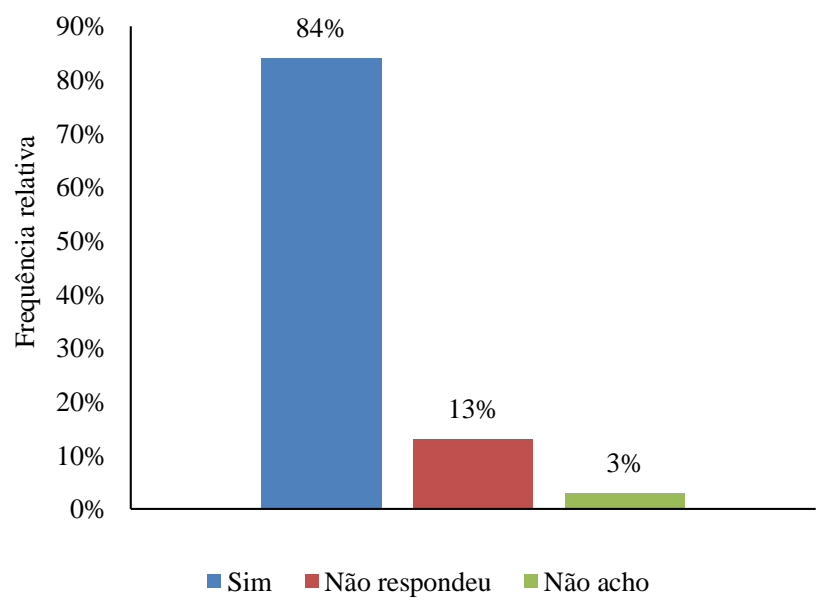

A conservação do meio se faz necessária, mas para isso é importante conhecer a dinâmica de interação entre os organismos em um determinado local. As abelhas são conhecidas por realizar um importante serviço para a natureza destacando o processo de polinização, na qual muitas são vistas como polinizadoras naturais de boa parte do que é produzido para a nossa alimentação. $O$ conhecimento da diversidade dos polinizadores e de sua interação com as espécies vegetais é de fundamental importância, uma vez que a polinização é um processo chave no que diz respeito a conservação de toda a biodiversidade (RODARTE et al., 2008). No que diz respeito aos cultivos agrícolas, estima-se que $75 \%$ sejam polinizadas por abelhas (FAO, 2004).

Com relação às formas de conservação do meio ambiente, os moradores das duas comunidades, se mostraram entendedores em relação aos problemas e suas possíveis soluções, pois $66,7 \%$ dos moradores afirmaram que uma das medidas viáveis para garantir a conservação do meio ambiente e de seus recursos, em especial as árvores melitófilas, seria conservar, preservá-las e não desmatar, o fato de não realizar a prática da queimada foi indicada por $7,2 \%$ dos entrevistados, porém $14,5 \%$ se mostraram não ter nenhuma ideia do que fazer em relação ao assunto e 11,6\% não responderam sobre nenhuma medida conservacionista. 
Mesmo com estes resultados, ainda é considerada significativa a visão dos moradores, pois se verifica que o conhecimento em relação a tais medidas, ainda é bem difundido na comunidade. A prática da agricultura familiar, algo comum na grande maioria das comunidades rurais, mediante o conhecimento popular, desempenha um grande papel na elaboração de estratégias de desenvolvimento sustentável (SANTOS et al., 2013).

Entre os moradores ainda persiste o pensamento conservacionistas de espécies vegetais melitófilas, porém, com relação ao que de fato é praticado na comunidade para conservar a flora melitófila, observa-se que as afirmativas em relação as práticas se mostraram opostas aos dados sobre o pensamento conservacionista, pois $62 \%$ dos entrevistados, afirmaram que atualmente não fazem nada em relação a alguma prática para preservar a vegetação melitófila, mesmo eles sabendo da importância de se conservar (Figura 3). Conhecer e ter em mente o pensamento conservacionista, mas não praticarem, se dá devido ao fato de que nas duas comunidades estudadas, os moradores atualmente não estão praticando a apicultura, mesma sendo uma atividade que auxilia na conservação de espécies, tanto vegetal como para a comunidade de abelhas. Segundo Benevides e Carvalho (2009), a apicultura não é uma atividade destrutiva e é uma das poucas atividades agropecuárias que preenche todos os requisitos do tripé da sustentabilidade, como o econômico que gera renda para os agricultores, o social que utiliza a mão de obra familiar no campo, diminuindo o êxodo rural; e o ecológico que não se desmata para criar abelhas.

$\mathrm{O}$ conhecimento, o plantio, assim como a comercialização destas árvores para a finalidade melitófila, não observada com atividade nas comunidades, exceto em que algumas casas, foi informado sobre a plantação de girassol, embora essa prática seja também relacionada a ornamentação do local. Assim, o estudo sobre o conhecimento local de uma comunidade é fundamental, pois busca compreender os valores que norteiam os sistemas de reciprocidades dessas comunidades com os ecossistemas, e a dimensão humana sobre a biodiversidade (SANTOS et al., 2013).

Figura 3. Ações praticadas pelos moradores para a conservação das espécies vegetais melitófilas em comunidades rurais do município de Sigefredo Pacheco, Estado do Piauí.

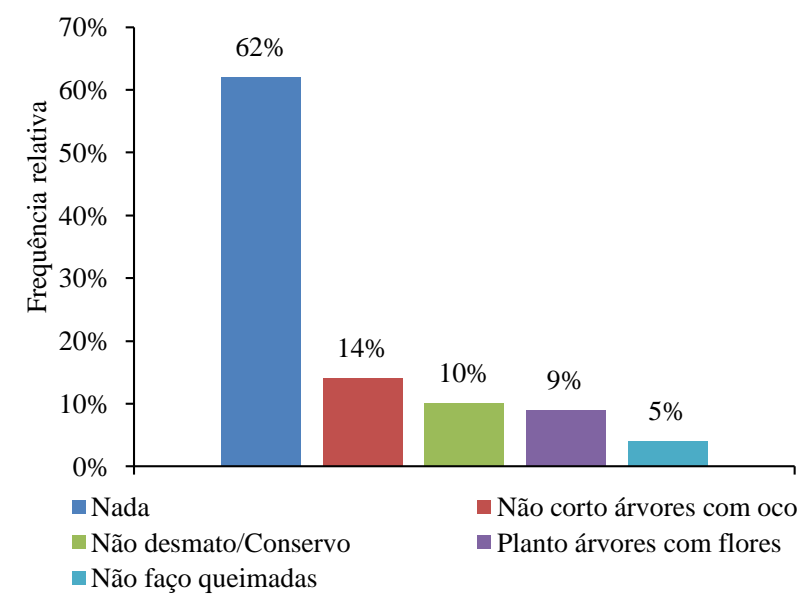

O estudo de comunidades rurais em seus mais variados aspectos, é que uma forma de reunir informações que auxiliam no fortalecimento da cultura e crenças, sendo esse valor agregado incalculável, e sua dimensão imensurável. Deste modo, conhecer a flora apícola é importante para a identificação das espécies vegetais utilizadas pelas abelhas (SODRÉ et al., 2008; DEMARTELAERE et al., 2010), e é a partir deste conhecimento que os produtores adquirem méis de boa procedência, e ainda procuram manter diferentes espécies vegetais em suas comunidades, pois percebem a sua importância para estes insetos. É através da diversidade das floradas existente nos Estados do Nordeste, que os produtores adquirem méis com características bastantes diferentes (ARRUDA, 2003).

Como a biodiversidade é alta, uma determinada espécie vegetal poderá apresentar em uma região características diferenciadas para o fornecimento de recursos florais para as abelhas que as visitam, isso se deve ao fator edafoclimático, sendo assim, o inventário da flora apícula deverá ser regional, uma vez que as espécies consideradas excelentes produtoras de néctar em uma região podem não ser em outra (SANTOS et al., 2006).

Seguindo este pensamento, os moradores informaram que não se sentem atraídos em relação as coletas de méis proveniente da florada da Licania rigida Benth (oiticica), pois segundo eles, as características que este mel apresenta, principalmente em relação a sua coloração esverdeada e sabor não é aceitável na comunidade. Segundo estes entrevistados o mel com boa qualidade para o consumo, seria aquele proveniente da floração da Myracrodruon urundeuva M.Allemão (aroeira), C. blanchetianus (marmeleiro) e do cajueiro (A. occidentale), sendo este, o mel de melhor procedência.

O mel produzido através do néctar da $M$. urundeuva, é saboroso e muito apreciado na estação seca, período com poucos recursos florais na região da caatinga, estas plantas são fundamentais para a alimentação das abelhas, e é devido as suas características melíferas que a mesmas são indicadas para o plantio em áreas de conservação e criação de abelhas; quanto ao $C$. blanchetianus, o néctar das suas flores é responsável pela produção de mel com sabor muito apreciado e com alto valor comercial para os criadores de abelhas do nordeste, assim como, auxilia na criação e conservação de abelhas sem ferrão (MAIA-SILVA et al., 2012).

Com relação ao cajueiro (A. occidentale), entende-se que na região Nordeste, em especial nos Estados do Ceará, Piauí e Rio Grande do Norte, existem grandes áreas de cultivo do cajueiro sendo o mesmo utilizado para a produção de castanha e pedúnculo, com isso, termina sendo uma cultura atrativa às abelhas melíferas, e a partir desta interação, é possível a produção de mel monofloral com grande valor comercial (BENDINI et al., 2008).

Mendes et al., (2009), descreve que este mel é proveniente da origem de flores de uma mesma família, gênero ou espécie e possui características sensoriais, físicoquímicas e microscópicas próprias. No Brasil, os méis monoflorais são produzidos por abelhas africanizadas, $A$. mellifera, ou por abelhas nativas, do gênero Meliponinae, e geralmente provenientes de floradas como as da $C$. aurantium (laranjeira) e do Eucalyptus spp (eucalipto) (QUEIROGA et al., 2015). Assim, tomando por base no que foi visto, em comunidades rurais os estudos que buscam compreender as plantas fornecedoras de recursos tróficos para as abelhas são 
importantes para preservação, manejo e também para produção apícola, pois, o potencial de produção apícola de uma região é determinado pelo revestimento florístico; grande parte da vegetação natural está sendo destruída, e isso se deve a degradação e devastação do meio ambiente, comprometendo assim a produção de mel e outros produtos das abelhas (VIDAL et al., 2008).

\section{CONCLUSÕES}

O conhecimento sobre plantas melitófilas é presente entre os moradores das comunidades rurais do município de Sigefredo Pacheco no Estado do Piauí, sendo as espécies com potencial melitófila que se destacaram foram a $C$. blanchetianus (marmeleiro) e o H. suaveolens (bambural), e a família botânica que teve maior representação foram a Anacardiaceae e Leguminosae. A variedade de planta também foi verificada, destacando assim 17 famílias botânicas. Na comunidade estudada, não existe a prática do plantio de espécies com potencial melitófila, porém, a espécie $H$. апnии (girassol), foi a única citada, não por conta do seu potencial melitófila, mas por seu valor ornamental.

O conhecimento sobre a flora melitófila em comunidades rurais proporciona práticas de conservação destas espécies na região, pois a partir destas informações passadas de uma geração a outra, medidas podem ser tomadas para recuperação de possíveis áreas degradadas, utilizando apenas espécies nativas que sejam favoráveis a atividade de apicultura e meliponicultura.

\section{REFERÊNCIAS}

ALBUQUERQUE, U. P.; ANDRADE, L. H. C. Uso de recursos vegetais da caatinga: o caso do agreste do estado de Pernambuco (Nordeste do Brasil). Interciencia, Caracas, v. 27, n. 7, 2002.

ALBUQUERQUE, U. P.; LUCENA, R. F. P.; NETO, E. M. F. L. Seleção e escolha dos participantes da pesquisa. In: ALBUQUERQUE, U. P.; LUCENA, R. F. P.; CUNHA, L. V. F. C. C. (orgs.). Métodos e técnicas na pesquisa etnobotânica. Recife, $2^{\mathrm{a}}$. ed. COMUNIGRAF p. 21- 40, 2008.

ALEIXO, D. L.; ARAÚJO, W. L.; AGRA, R. S. A.; MARACAJÁ, P. B.; SOUSA, M. J. O. Mapeamento da flora apícola arbórea das regiões pólos do estado do Piauí. Revista Verde, Pombal, v. 9, n. 4, p. 262 - 270, 2014.

ARRUDA, C. M. F. Características físico-quimicas e polínicas de amostra de méis de Apis melífera L., 1758 (Hymenoptera, Apidae) da região da Chapada do Araripe, município de Santana do Cariri, estado do Ceará. 2003. 86f. Dissertação (Mestrado). Escola Superior Luiz de Queiroz, Piracicaba - SP. 2003.

AYANTUNDE, A. A.; BRIEJER, M.; HIERNAUX, P.; UDO, M. H.; TABO, R. Botanical knowledge and its differentiation by age, gender and ethnicity in southwestem niger. Human Ecology, v. 36, p. 881-889, 2008.

BEGOSSI, A. Ecologia Humana. In: Begossi, A. (org.). Ecologia de Pescadores da Mata Atlântica e da Amazônia. São Paulo, Fapesp/Hucitec. 332p, 2004.
BEGOSSI, A. Ecologia humana: Um enfoque das relações homem-ambiente. Interciencia, Caracas, v. 18, n. 1, p. 121132, 1993.

BENDINI, J. N; SOUZA, D. C. Caracterização físico-química do mel de abelhas proveniente da florada do cajueiro. Ciência Rural, Santa Maria, v. 38, n. 2, p. 565-567, 2008.

BENEVIDES, D. S.; CARVALHO, F. G. Levantamento da flora apícola presente em áreas de caatinga do município de Caraúbas - RN. Sociedade e Território, Natal, v. 21, n. 1 - 2, p. 44-54, 2009.

BERNARD, H. R. Research in Cultural Anthropology. Sage. Newbury Park, CA, EEUU, 1988.

CAMOU-GUERREIRO, A.; REYES-GARCÍA, V.; MARTÍNEZ-RAMOS, M.; CASAS, A. Knowledge and use value of plant species in a rarámuri community: a gender perspective for conservation. Human Ecology, v. 36, n. 2, p. 259-272, 2008

CEPRO (Fundação Centro de Pesquisas Econômicas e Sociais do Piauí) (2013). Diagnostico socioeconômico do município de Sigefredo Pacheco. Disponível em: <http://www.cepro.pi.gov.br/download/201106/CEPRO21_8 029356bf4.pdf> Acesso em 08/ março de 2016.

CHAVES, E. M. F.; BARROS, R. F. M.; ARAÚJO, F. S. Flora apícola do carrasco no municipio de Cocal, Piauí, Brasil. In: $57^{\circ}$ Congresso Nacional de Botânica, 2007, Gramado. Revista Brasileira de Biociências. Porto Alegre: Intituto de Biociências da Universidade Federal do Rio Grande do Sul, v. 5, p. 555-557, 2006 .

CHAVES, E. M. F.; BARROS, R. F. M.; SÉRVIO JÚNIOR, E. M. Plantas do carrasco da Ibiapaba. Fundação de Amparo à Pesquisa do Estado do Piauí (2006b). Disponível em: <http://www.fapepi.pi.gov.br/carrasco> Acesso em 08 de Jul. de 2016 .

COSTA, J. M. Estudos fitossociológico e sócio-ambiental de uma área de cerrado com potencial melitófilo no municipio de Castelo do Piauí, Piauí, Brasil. Teresina: UFPI, 2005. 109p. Dissertação (Mestrado) - Programa de Pós-Graduação em Desenvolvimento e Meio Ambiente, Universidade Federal do Piauí, Teresina, 2005.

COSTA, J. M.; CASTRO, A. A. J. F. Flora e melissofauna associada de um cerrado rupestre da região setentrional do Paiuí, p. 271-298. In: LOPES, W. G. R.; ARAÚJO, J. L. L.; MOITA NETO, J. M.; BARROS, R. F. M. (Org.) Cerrado Piauiense: uma visão multidisciplinar. Teresina, EDUFPI, (Série Desenvolvimento e Meio Ambiente) 402p., 2007.

COSTA, R. A. A identidade e o conhecimento Etnobotânico dos moradores da Floresta Nacional do Amapá. 2013. 104 f. Dissertação (Mestre em Biodiversidade Tropical), Fundação Universitária Federal do Amapá, 2013. 
CRONQUIST, A. An integrated system of classification of flowering plants. New York: Columbia Universaty Press 1262p. 1981.

DEMARTELAERE, A. C. F.; OLIVEIRA, A. K.; GÓES, G. B.; LIMA, G. K. L.; PEREIRA, M. F. S. A flora apícola no semi-árido brasileiro. Revista Verde, Mossoró, v. 5, n. 1, p. 17-22, 2010.

FAO. Conservation and management of pollinators for sustainable agriculture $\tilde{\mathrm{n}}$ the international response. In: FREITAS, B.M.; PEREIRA, J. O. P. Solitary bees: conservation, rearing and management for pollination. Fortaleza: Imprensa Universit·ria, p 2-19, 2004.

FLORA DO BRASIL. 2016. Disponível em: < www.floradobrasil.jbrj.gov.br/ > . Acesso em: 11 jul. 2016.

GANDOLFI, E. S.; HANAZAKI, N. Etnobotânica e urbanização: conhecimento e utilização de plantas de restinga pela comunidade nativa do distrito do Campeche (Florianópolis, SC). Acta Botanica Brasilica, Belo Horizonte, v. 25 , n. 1 , p. $168-177,2011$.

GIRALDI, M.; HANAZAKI, N. Uso e conhecimento tradicional de plantas medicinais no sertão do Ribeirão, Florianópolis, SC, Brasil. Acta Botanica Brasilica, Belo Horizonte, v. 24, n. 2, p. 395-406, 2010.

GIULIETTI, A. M. D. U.; BOCAGE, NETA, A. L.; CASTRO, A. A. J. F.; GAMARRA-ROJAS, C. F. L.; SAMPAIO, E. V. S. B.; VIRGÍNIO, J. F.; QUEIROZ, L. P.; FIGUEIREDO, M. A.; RODAL, M. J. N.; BARBOSA, M. R. V.; HARLEY, R. M. Diagnóstico da vegetação nativa do bioma Caatinga. In Biodiversidade da Caatinga: áreas e ações prioritárias para a conservação (J.M.C. Silva, M. Tabarelli, M.T. Fonseca \& L.V. Lins, orgs.). MMA, UFPE, Conservation International do Brasil, Fundação Biodiversitas, Embrapa Semi-Árido, Brasília, p. 48-90, 2004.

GRZEBIELUKA, D. Por uma tipologia das comunidades tradicionais brasileiras. Revista Geografar, Curitiva, v. 7, n. 1, p. 116-137, 2012.

IBGE (Instituto Brasileiro de Geografia e Estatística) (2010). Censo demográfico 2010. Aspectos físicos de Sigefredo Pacheco. Disponível em: <http://www.ibge.gov.br/cidadesat/topwindow.htm?1>. Acesso em: 08/ março de 2016.

JUDD, W.S.; CAMPBELL, C.S.; KELLOGG, E.A.; STEVENS P.F. Plant systematics: a phylogenetic approach. Sinauer associates, Sunderland, 462p, 1999.

PEREIRA JÚNIOR, P. G.; SILVA, T. A.; SILVA, S. I. Notas Etnobotânicas Sobre Flora Apícola em Fragmentos de Mata Atlântica Inseridos nas Comunidades Circunvizinhas à Reserva Florestal de Dois Irmãos, Recife -PE. Revista Eletrônica de Biologia, Sorocaba, v. 5, n. 3, p. 77- 91, 2012.

LUCENA, R. F. P.; FARIAS, D. C.; CARVALHO, T. K. N.; LUCENA, C. M. L.; NETO, C. F. A. V.; ALBUQUERQUE,
U. P. Uso e conhecimento da aroeira (Myracrodruon urundeuva) por comunidades tradicionais no Semiárido brasileiro. Sitientibus série Ciências Biológicas, v. 11, n. 2, p. 255-264, 2011.

MAIA-SILVA, C.; SILVA, C. I.; HRNCIR, M. QUEIROZ, R. T.; IMPERATRIZ-FONSECA, V. L. Guia de plantas: visitadas por abelhas na Caatinga. 1. ed. Fortaleza, CE: Editora Fundação Brasil Cidadão, 2012.

MENDES, C. G.; SILVA, J. B. A.; MESQUITA, L. X.; MARACAJÁ, P. B. As análises de mel: revisão. Caatinga, Mossoró, v. 22, n. 2, p. 07-14, 2009.

MENDONÇA, K.; MARCHINI, L. C.; SOUZA, B. A.; ALMEIDA-ANACLETO, D.; MORETI, A. C. C. C. Plantas apícolas de importância para Apis mellifera L. (Hymenoptera: Apidae) em fragmento de cerrado em Itirapina, SP. Neotropical Entomology, v. 37, n. 5, p.513-521, 2008.

MISSOURI BOTANICAL GARDEN (MOBOT). 2016. Disponível em:<www.missouribotanicalgarden.org/ >. Acesso em: 11 jul. 2016.

MONTE, A. M.; AZEVEDO, M. L. X.; FILHO, F. C. C.; RODRIGUES, A. M. D.; MOURA, S. G.; MURATORI, M. C. S. Qualidade de méis de abelhas nativas sem ferrão do estado do Piauí, Brasil. Revista Brasileira de Medicina Veterinária, Rio de Janeiro, v. 35, n. 1, p. 48-54, 2013.

MORETI, A. C. C. C.; ANACleto, D. A.; ÁVILA, M.; VIEIRA, G. H. C.; MARCHINI, L. C. Abelhas visitantes em vegetação de diferentes áreas remanescentes de cerrado. Magistra, Cruz das Almas, v. 18, n. 4, p.229-248, 2006.

MORI, S. A.; SILVA, L. A. M., LISBOA, G.; CORADIM, L. Manual de manejo do herbário fanerogâmico. 2. ed. Ilhéus: CEPLAC, 104p, 1989.

MOURA, S. G. Qualidade do mel de abelhas (Apis mellifera L.) em função do ambiente e do tempo de armazenamento. Dissertação (Ciência Animal) - Universidade Federal do Piauí, Teresina. 2006. 64p. Disponível em: http://www. ufpi.br/subsiteFiles/ciencianimal/arquivos/files/DM_ SGM.pdf. Acesso em: 12 jul 2016.

NEGRELLE, R. R. B; FORNAZZARI, K. R. C. Estudo etnobotânico em duas comunidades rurais (Limeira e Ribeirão Grande) de Guaratuba (Paraná, Brasil). Revista Brasileira de Plantas Medicinais, Botucatu, v. 9, n. 2, p. 36-54, 2007.

OLIVEIRA, F. C; ALBUQUERQUE, U. P; FONSECA KRUEL, V. S; HANAZAKI, N. Avanços nas pesquisas etnobotânicas no Brasil. Acta Botanica Brasilica, v. 23, n. 2, p. 590-605, 2009.

PINHEIRO, M.; ABRÃO, B. E.; HARTER-MARQUES, B.; MIOTTO, S. T. S. Floral resources used by insects in a grassland community in southern Brazil. Revista Brasileira de Botânica, São Paulo, v.31, p.469-489, 2008. 
QUEIROGA, C. F. M. A.; FILHO, F. G. L.; MACHADO, A. V.; COSTA, R. O. Cadeia Produtiva do Mel de Abelhas: Fonte Alternativa de Geração de Renda para Pequenos Produtores e Qualidade Físico-química do Mel. Revista Brasileira de Agrotecnologia, Garanhuns, v. 5, n. 1, p. 24-30, 2015.

RODARTE, A. T. A; SILVA, F. O; VIANA, B. F. A flora melitófila de uma área de dunas com vegetação de caatinga, Estado da Bahia, Nordeste do Brasil. Acta botanica Brasilica, v. 22, n. 2, p. 301-312, 2008.

SALIS, S. M.; JESUS, E. M.; REIS, V. D. A.; ALMEIDA, A. M.; PADILHA, D. R. C. Calendário floral de plantas melíferas nativas da Borda Oeste do Pantanal no Estado do Mato Grosso do Sul. Pesquisa Agropecuária Brasileira. Brasília, v. 50, n.10, p.861-870, 2015.

SAMPAIO, E. V. S. B. OVERVIEW of the Brazilian caatinga. Em Bullock SH, Medina E. (Eds,) Seasonally dry tropical forests. Cambridge University Press. New York, p. 35-63, 1995.

SANTOS, A. S; OLIVEIRA, L. C. L; CURADO, F. F; AMORIM, L. O. Caracterização e desenvolvimento de quintais produtivos agroecológicos na comunidade Mem de Sá, Itaporanga d'Ajuda-Sergipe. Revista Brasileira de Agroecologia, v. 8, n. 2, p. 100-111, 2013.

SANTOS, R. F.; KILL, L. H. P.; ARAÚJO, J. L. P. Levantamento da flora melífera de interesse apícola no município de Petrolina-PE. Caatinga, Mossoró, v. 19, n. 3, p. 221-227, 2006.

SILVA, G. A. R.; BASTOS, E. M.; SOBREIRA, J. A. R. Levantamento da flora apícola em duas áreas produtoras de mel no estado do Piauí. ENCICLOPÉDIA BIOSFERA, Centro Científico Conhecer - Goiânia, v. 10, n. 18, p. 330533162014.

SILVA, L. E.; QUADROS, D. A.; NETO, A. J. M. Estudo etnobotânico e etnofarmacológico de plantas medicinais utilizadas na região de Matinhos - PR. Ciência e Natura, v. 37 n. 2 , p. $266-276,2015$.

SILVA. M. P. Etnobotânica de comunidades rurais da Serra de Campo Maior - Piauí, Brasil. Teresina: UFPI, 2010. 171p. Dissertação (Mestrado) - Programa de Pós-Graduação em Desenvolvimento e Meio Ambiente. Universidade Federal do Piauí, Teresina, 2010.

SOARES, S. M. N. A. Levantamento da flora melitófila e himenofauna associada no cerrado no município de Floriano, Piauí, Brasil. 2007. Monografia. (Bacharelado em Ciências Biológicas) - Universidade Federal do Piauí, Teresina, 2007.

SODRÉ, G. S.; MARCHINI, L. C.; MORETI, A. C. C. C.; CARVALHO, C. A. L. Tipos polínicos encontrados em amostras de méis de Apis mellifera em Picos, Estado do Piauí. Revista Ciência Rural, Santa Maria, v. 38, n. 3, p. 839-842, 2008.
SOUSA, L. S. Flora melitófila e abelhas ocorrentes no Parque Ambiental Paquetá, município de Batalha, Piauí. 2007. Monografia. (Bacharelado em Ciências Biológicas) Universidade Federal do Piauí, Teresina, 2007.

SYLVESTRE, L.S.; ROSA, M.M.T. 2002. Manual Metodológico para Estudos Botânicos na Mata Atlântica. EDUR, Seropédica - RJ. 123p.

TORQUATO, T. G. M. Levantamento das especies vegetais melitofilas ocorrente no Quilombo Olho d'água dos Pires, Esperantina, Piauí, Brasil. 2006. 110f. Dissertação (Mestrado) Desenvolvimento e Meio Ambiente - Universidade Federal do Piauí, Teresina, 2006.

TORRES, D. F.; OLIVEIRA, E. S.; ALVES, R. R. N.; VASCONCELLOS, A. Etnobotânica e Etnozoologia em unidades de conservação: uso da biodiversidade na APA de Genipabu, Rio Grande do Norte, Brasil. Interciencia, v. 34, n. 9, p. 623-629, 2009.

TROVÃO, D. M. B. M.; SOUZA, B. C.; CARVALHO, E. C. D.; OLIVEIRA, P. T. B.; FERREIRA, L. M. R. Espécies vegetais da caatinga associadas às comunidades de abelhas (Hymenoptera: Apoidea: Apiformis). Caatinga, Mossoró, v. 22, n. 3, p 136-143, 2009.

VIANA, B. F.; SILVA, F. O.; KLEINERT, A. M. P. A flora apícola de uma área restrita de dunas litorâneas, Abaeté, Salvador, Bahia. Revista Brasileira de Botânica, São Paulo, v. 29, n. 1, p. 13-25, 2006.

VIDAL, M. G.; SANTANA, N. S.; VIDAL, D. Flora apícola e manejo de apiários na região do Recôncavo Sul da Bahia. Revista Acadêmica Ciência Agrária Ambiental, Curitiba, v. 6 n. 4, p. 503-509, 2008.

VIEIRA, F. J. Uso e diversidade dos recursos vegetais utilizados pela comunidade quilombola dos Macacos, São Miguel dos Tapuio, Piauí. Teresina: UFPI, 2008. 124p. Dissertação (Mestrado) - Programa de Pós-Graduação em Desenvolvimento e Meio Ambiente. Universidade Federal do Piauí, Teresina, 2008).

VIEIRA, G. H. C.; MARCHINI, L. C.; SOUZA, B. A.; MORETI, A. C. C. C. Fontes florais usadas por abelhas (Hymenoptera, Apoidea) em área de cerrado no Município de Cassilândia, Mato Grosso do Sul, Brasil. Ciência e Agrotecnologia, Lavras, v. 32, n. 5, p.1454-1460, 2008.

VIU, A. F. M; VIU, M. A. O; CAMPOS, L. Z. O. Etnobotânica: uma questão de gênero? Revista Brasileira de Agroecologia, Porto Alegre, v. 5. n. 1, p. 138-147, 2010. 